\title{
Effects of high hydrostatic pressure on the overall quality of Pêra-Rio orange juice during shelf life
}

\author{
Paz Spira ${ }^{1}$, Antonio Bisconsin-Junior ${ }^{1} \oplus$, Amauri Rosenthal ${ }^{2}$ and \\ Magali Monteiro' ${ }^{1}\left({ }_{0}\right.$
}

\begin{abstract}
The effect of high hydrostatic pressure on antioxidant activity, total phenolic compounds, physicochemical characteristics, color, pectin methylesterase activity, and microbiological count were evaluated during the shelf life of Pêra-Rio orange juice. Pressurized $\left(520 \mathrm{MPa}, 60^{\circ} \mathrm{C}\right.$, for $\left.360 \mathrm{~s}\right)$, non-processed and pasteurized $\left(95^{\circ} \mathrm{C} / 30 \mathrm{~s}\right)$ orange juice were compared at zero time of storage. Pressurized and pasteurized juices were studied during a refrigerated 90-day shelf life. Pressurization did not cause expressive change in physicochemical characteristics of Pêra-Rio orange juice along shelf life, but significantly reduced pectin methylesterase residual activity to $13 \%$ and microbiological counts below detection levels up to 68 days of storage, with small counts $(30.0 \times 10 \mathrm{CFU} / \mathrm{mL}$ mesophilic aerobic bacteria and $20.7 \times 10 \mathrm{CFU} / \mathrm{mL}$ yeast and mold) at 90 days, capable of ensuring the juice's stability along shelf life. Lightness $\left(L^{*}\right)$ and $b^{*}$ values were significantly reduced by high hydrostatic pressure during shelf life, while $a^{*}$ values were significantly higher. Ascorbic acid decreased around $80 \%$ during shelf life. Antioxidant activity remained stable after processing and during storage.
\end{abstract}

\section{Keywords}

High hydrostatic pressure, orange juice, shelf life, antioxidant activity, physicochemical characteristics, microbiological count

Date received: 8 June 2017; accepted: 20 February 2018

\section{INTRODUCTION}

Brazil is the largest producer and exporter of orange juice worldwide, withholding $61.3 \%$ of the global production in the $2015 / 2016$ harvest. Of the nearly 300 million orange boxes, weighing $40.8 \mathrm{~kg}$ each, produced in the 2015/2016 harvest, $15 \%$ were consumed in natura and $85 \%$ were destined to the industry. Brazil produced 531 mil ton of frozen concentrated orange juice (FCOJ) and 240 mil ton of not from concentrate (NFC) FCOJ equivalent orange juice in the 2015/2016 harvest. The country exports $98 \%$ of the orange juice it produces, mostly to European countries $(70 \%)$, the United States (25\%), and Japan (3\%) Instituto de Economia Agrícola (IEA), 2017; Secretaria de

Food Science and Technology International 24(6) 507-518

(C) The Author(s) 2018 Article reuse guidelines:

sagepub.com/journals-permissions

DOI: $10.1177 / 1082013218768997$

journals.sagepub.com/home/fst

๑SAGE
Comércio Exterior (SECEX), 2017; United States Department of Agriculture (USDA), 2017). The Brazilian citriculture numbers are expressive - out of five glasses of orange juice consumed worldwide, three come from the Brazilian production (CITRUSBR, 2017).

In recent years, a new trend has been observed regarding orange juice consumption of NFC rather than FCOJ. This could be explained by the fact that the NFC juice is exposed a shorter time to high temperatures when compared to FCOJ, resulting in less drastic flavor and aroma modifications (Janzantti et al., 2011).

\footnotetext{
${ }^{1}$ Department of Food and Nutrition, School of Pharmaceutical Science, São Paulo State University - UNESP, Araraquara, Brazil ${ }^{2}$ Embrapa Food Technology, Av. das Américas, 29501, Rio de Janeiro, RJ, Brazil

Corresponding author:

Magali Monteiro, Department of Food and Nutrition, Rodovia Araraquara-Jau, km 01, Campus, 14800-903 Araraquara-SP, Brazil.

Email: monteiro@fcfar.unesp.br
} 
Thermal treatment is still the most used processing treatment for orange juice due being able to destroy microorganisms and inactivate enzymes. However, the intense time/temperature conditions may reduce natural and characteristic flavor and ascorbic acid (AA), affecting the juice's overall quality (Janzantti et al., 2011).

The fruit juice industry has been looking into innovative technologies, which use minimal heat treatment and are able to produce juice with more natural-like characteristics, in order to preserve flavor and nutritional aspects, complying with the consumption trend that searches for healthy and flavorful products (Deliza et al., 2005). High hydrostatic pressure (HHP) reduces orange juice contaminating microflora and the enzyme pectin methylesterase's (PME) activity (Nienaber and Shellhammer, 2001) by using pressure instead of high temperature, therefore preserving its sensory and nutritional aspects. Several PME isoenzymes are associated with cloud loss, attributed its endogenous activity, which demethoxylates soluble pectins causing calcium pectates precipitation and clarification of the juice (Versteeg et al., 1980). Cloud stability is an important quality aspect of orange juice, since it positively affects turbidity, flavor, and color characteristics of the juice. A low PME residual activity, however, could still preserve cloud stability during the shelf life of the juice (Bisconsin-Junior et al., 2014).

In addition, color, soluble solids, $\mathrm{pH}$, carotenoid content, and bioactive compounds of orange juice are not considerably affected by HHP (Baxter et al., 2005; Bull et al., 2004; Timmermans et al., 2011; Vervoort et al., 2011).

Although HHP is a well researched technology, to the best of our knowledge, the shelf life study of the Pêra-Rio orange juice has not yet been developed. This technology is still not being used by the Brazilian juice industry, which presents itself as a whole range of opportunities. Bull et al. (2004) reported that Valencia orange juice treated at $600 \mathrm{MPa}, 20^{\circ} \mathrm{C}$ for $60 \mathrm{~s}$ did not affect AA significantly, however a different study found $11 \%$ reduction in $\mathrm{AA}$ of the juice treated at $100 \mathrm{MPa}$, $60{ }^{\circ} \mathrm{C}$ during $300 \mathrm{~s}$ (Sánchez-Moreno et al., 2005). Sánchez-Moreno et al. (2005) reported that after 400 $\mathrm{MPa}, 40^{\circ} \mathrm{C}$ for $60 \mathrm{~s}$, orange juice showed no significant reduction on vitamin $\mathrm{C}$, but presented higher extractability of carotenoids (54\%) and flavanones (34\%), and no significant difference on antioxidant activity.

The HHP conditions applied in this work were chosen through the results of an optimization study (Bisconsin-Junior et al., 2014), which applied the response surface methodology to evaluate the effect of pressure, temperature and time on PME activity and total counts of aerobic microorganisms, yeasts, and molds. A central composite design (CCD) of three independent variables (pressure, time and temperature) with five levels and 17 experiments was used (Rodrigues and Iemma, 2009). The increase in pressure (100 to 600 $\mathrm{MPa}$ ), temperature $\left(30\right.$ to $60^{\circ} \mathrm{C}$ ), and time (30 to $360 \mathrm{~s})$ promoted the reduction on the PME residual activity from CCD (15.4\% to $107.9 \%)$ and aerobic microorganism count of orange juice. The optimal condition (520 MPa, $60^{\circ} \mathrm{C}$, for $360 \mathrm{~s}$ ) was defined based on its capacity to reduce PME residual activity below $20 \%$ and microbial count lower than $2 \log \mathrm{CFU} / \mathrm{mL}$. However, these were not necessarily the same conditions for maintaining optimal vitamin $\mathrm{C}$ levels and bioactive compounds activity (Bisconsin-Junior et al., 2015). A different study (Torres et al., 2015), which evaluated the effects of pressure, temperature, and time on orange juice with combinations ranging from 250 to $500 \mathrm{MPa}, 25$ to $65^{\circ} \mathrm{C}$ and 1 to $30 \mathrm{~min}$, found that a $6.5 \log$ cycle reduction was obtained at $400 \mathrm{MPa}$ for $3 \mathrm{~min}$ at $25^{\circ} \mathrm{C}$. However, in order to inactivate at least $90 \%$ of PME activity the ideal conditions were 500 $\mathrm{MPa}$, at $50^{\circ} \mathrm{C}$ for $15 \mathrm{~min}$, corroborating with idea that enzyme inactivation requires more severe conditions, as shown by the optimization study.

The aim of this study was to evaluate the effect of HHP treatment on the quality aspects of the Pêra-Rio orange juice during shelf life, thus offering knowledgeable insight to the citrus industry, enabling it to be produced and commercialized both domestically and abroad.

\section{MATERIALS AND METHODS Chemicals and materials}

Citrus pectin, ABTS diammonium salt, 2,4,6-tris(2-pyridyl)-s-triazine, 2,2-diphenyl-1-picrylhydrazyl, 6hydroxy-2,5,7,8-tetramethylchroman-2-carboxylic acid (Trolox), and gallic acid were obtained from SigmaAldrich (St Louis, MO); AA and glucose purchased from Merck (Darmstadt, Alemanha); Folin-Ciocalteu reagent from Imbralab (Ribeirão Preto, SP, Brazil); potassium persulfate from Fluka (Steinheim, Germany); methanol from JT Baker (Philipsburg, PA); sodium carbonate, sodium hydroxyl, potassium sodium tartrate tetrahydrate, cupric sulfate pentahydrate, and potassium phosphate dibasic from Labsynth (Diadema, SP, Brazil); oxalic acid and 2,6-dichloroindophenol sodium salt hydrate from Vetec (Rio de Janeiro, RJ, Brazil); Petrifilm ${ }^{\mathrm{TM}}$ used for counting mesophilic aerobic bacteria, thermotolerant and total coliforms, mold and yeast was obtained from $3 \mathrm{M}^{\mathrm{TM}}$ (St. Paul, MN).

\section{Orange juice}

Oranges from the Pêra-Rio variety were provided by a citrus industry from Araraquara, SP, Brazil. The fruit were cultivated in the region of Bauru, SP, Brazil 
(22 25' 59" S; 49 10'31" W), during the 2012/2013 harvest. The oranges were processed at JBT FoodTech Citrus System in Araraquara, SP. Before the extraction, the fruit and the equipment were sanitized using water aspersion, and later submerged in a sodium hypochlorite solution $(100 \mathrm{mg}$ of chlorine/L) for $10 \mathrm{~min}$. The extraction itself was performed in the JBT 391B extractor, using ideal configuration for obtaining NFC (not from concentrate) juice and premium juice extractor settings with a UFC-35 finisher $(0.25 \mathrm{~mm}$ sieve $)$.

\section{HHP treatment}

For the HHP treatment, the orange juice $(100 \mathrm{~mL})$ was packaged in heat sealed, polyethylene (PE) bags (Selovac 200B II, Selovac, São Paulo, Brazil). The juice was pressurized, according to the experimental design, in a Stansted Food Lab 9000 (Stansted Fluid Power, Stansted, UK). The treatment conditions were previously defined in an optimization study (BisconsinJunior et al., 2014). The chosen pressurization conditions were $520 \mathrm{MPa}, 60^{\circ} \mathrm{C}$, for $360 \mathrm{~s}$, which are capable of producing orange juice with residual enzyme PME activity lower than $20 \%$ and aerobic microorganism count lower than $2 \log \mathrm{CFU} / \mathrm{mL}$. The HHP equipment has a $500 \mathrm{~mL}$ pressure vessel with a maximum nominal operation pressure of $900 \mathrm{MPa}$ and a temperature range from $-20^{\circ} \mathrm{C}$ to $90^{\circ} \mathrm{C}$. The temperature in the vessel is controlled by liquid circulation in the outer layer connected to a heating-cooling system. The pressure transmitting fluid used was $70 \%(\mathrm{v} / \mathrm{v})$ ethanol. The compression rate was $3.5 \mathrm{MPa} / \mathrm{s}$ and the decompression time was less than $10 \mathrm{~s}$. During the treatment, the temperature and pressure inside the pressure vessel were monitored (Bisconsin-Junior, et al., 2015).

\section{Pasteurization of the orange juice}

The orange juice was pasteurized using the Armfield FTD25D SSHE (Armfield, UK) tubular heat exchanger at $95^{\circ} \mathrm{C}$ for $30 \mathrm{~s}$ (Braddock, 1999), and later cooled to $20^{\circ} \mathrm{C}$. Afterwards, the juice was packaged aseptically in PE flasks $(500 \mathrm{~mL})$.

\section{Physicochemical analysis}

The physicochemical parameters of the non-processed, pasteurized, and pressurized orange juice were evaluated. Soluble solids (method no 932.12), total titratable acidity (method no 942.15), pH (method no 945.27), total and reducing sugars (method no 925.36) were analyzed according to Association of Official Analytical Chemists (AOAC, 2011), and ratio was calculated (soluble solids/total titratable acidity). All analyses were performed in triplicate.

\section{Pectin methylesterase}

The PME activity was evaluated according to Hagerman and Austin (1986), as reported by Bisconsin-Junior et al. (2014). Orange juice and $\mathrm{NaCl}$ $(8.8 \%, \mathrm{w} / \mathrm{v})$ were homogenized $(4.5: 15, \mathrm{w} / \mathrm{v})$ and centrifuged $\left(18,000 \mathrm{~g} / 20 \mathrm{~min}\right.$ at $\left.4{ }^{\circ} \mathrm{C}\right)$. The supernatant was collected and used as the enzymatic extract. The substrate was composed of citrus pectin solution $(0.5 \%$, $\mathrm{w} / \mathrm{v})$, bromothymol blue $(0.01 \%, \mathrm{w} / \mathrm{v})$ in potassium phosphate buffer $(0.003 \mathrm{M})$ and distilled water. The substrate and enzymatic extract were adjusted to $\mathrm{pH}$ 7.5. Substrate was added to the enzymatic extract $(20 \mu \mathrm{L})$ and the pectin hydrolysis reaction was monitored by the absorbance decrease at $620 \mathrm{~nm}$ using a spectrophotometer (Evolution 220, Thermo Scientific, USA), and water as blank. PME activity analyses were performed in triplicate, at $25^{\circ} \mathrm{C}$ and results expressed as PME residual activity $(\%)$.

\section{Microbiological analysis}

Orange juice $(10 \mathrm{~mL})$ was added to $90 \mathrm{~mL}$ sterilized buffered peptone water (BPW). After homogenization, aliquots were serially diluted in BPW and $1 \mathrm{~mL}$ of each dilution was inoculated onto Petrifilm ${ }^{\text {TM }} 3$ MTM plates for thermotolerant and total coliforms, mesophilic aerobic bacteria, yeast, and mold counts. The thermotolerant and total coliforms, and aerobic microorganisms count were performed after incubation at $35 \pm 1{ }^{\circ} \mathrm{C}$ for $48 \pm 3 \mathrm{~h}$ and the yeast and mold count after incubation at $25 \pm 1{ }^{\circ} \mathrm{C}$ for $120 \pm 6 \mathrm{~h}$. The minimum level of detection was $10 \mathrm{CFU} / \mathrm{mL}$ (AOAC, 2011). The analyses were performed in triplicate.

\section{Color measurement}

Konica Minolta CM 600D (Konica Minolta Sensing, Osaka, Japan) spectrophotometer was used (MeléndezMartínez et al., 2005) to measure color $\left(D_{65}\right.$ light source, $10^{\circ}$ observation angle, $8 \mathrm{~mm}$ opening). The orange juice was placed in a quartz cell of $10 \mathrm{~mm}$ optic path length $(50 \times 38 \times 10 \mathrm{~mm}) . L^{*}$ (lightness/ darkness), $a^{*}$ (redness/greenness), and $b^{*}$ (yellowness/ blueness) parameters were evaluated. Additionally, chroma (color saturation), Hue angle, and total color difference were calculated. The analyses were performed at $25^{\circ} \mathrm{C}$, in quintuplicate.

\section{Assessment of bioactive compounds and antioxidant capacity}

Ascorbic acid. Ascorbic acid analysis was based on the reduction of 2,6-dichloroindophenol (method $\mathrm{n}^{\mathrm{o}}$ 967.21) (AOAC, 2011). The analyses were performed 
in triplicate and the results were expressed as $\mathrm{mg}$ of $\mathrm{AA} / 100 \mathrm{~mL}$ of orange juice.

Extraction of bioactive compounds. The extraction was based on the procedure described by Asami et al. (2003). Orange juice $(5.00 \mathrm{~mL})$ and a methanol:water solution $(10 \mathrm{~mL}, 80: 20, \mathrm{v} / \mathrm{v})$ were vortexed $(1 \mathrm{~min})$, sonicated $(15 \mathrm{~min})$, and centrifuged $(10,000 \mathrm{~g} / 20 \mathrm{~min}$ at $20^{\circ} \mathrm{C}$ ). The supernatant was collected and the residue was submitted to the extraction procedure once again under the same conditions. Then supernatants were joined and submitted to total phenolic compounds (TPC) and antioxidant activity analyses.

Total phenolic compounds. The TPC were determined as described by Asami et al. (2003) and Singleton et al. (1999). Orange juice extract $(0.4 \mathrm{~mL})$ was added to the Folin-Ciocalteu reagent $(0.12 \mathrm{~mL})$. After $6 \mathrm{~min}$, a sodium carbonate solution $(4 \mathrm{~mL}, 70 \mathrm{~g} / \mathrm{L})$ was added and the volume fixed to $10 \mathrm{~mL}$ with water. The absorbance was measured at $730 \mathrm{~nm}$ using a spectrophotometer (Evolution 220, Thermo Scientific, EUA) and compared to a gallic acid calibration curve, with concentrations ranging from 72 to $200 \mathrm{mg} / \mathrm{L}$. The analyses were performed in triplicate and results expressed as $\mathrm{mg}$ of gallic acid equivalent/100 mL of orange juice.

A correction factor was calculated to discount AA, since it responds to the Folin-Ciocalteu reaction. Ascorbic acid standard solutions were prepared in concentrations that corresponded to the same range found in orange juice, and submitted to FolinCiocalteu reaction. The results, expressed as $\mathrm{mL}$ of gallic acid equivalent $/ 100 \mathrm{~mL}$ juice provided a correction factor of 0.389 , which was deducted from the previously obtained TPC values.

Antioxidant activity. The antioxidant activity was evaluated with $\mathrm{ABTS}^{+}$, as reported by Rufino et al. (2010). ABTS $(5.0 \mathrm{~mL}, 7 \mathrm{mmol} / \mathrm{L})$ was added to potassium persulfate $(88 \mu \mathrm{L}, 140 \mathrm{mmol} / \mathrm{L})$ to form the ABTS radical solution. The solution was stored protected from light for $16 \mathrm{~h}$ to ensure the complete formation of a stable radical. The ABTS radical solution was diluted with ethanol up to an absorbance of $0.70 \pm 0.05$ at $753 \mathrm{~nm}$. Three solutions of orange juice extract:ethanol were prepared $(1: 3 ; 2: 5$ and $1: 2 \mathrm{v} / \mathrm{v})$. A $30 \mu \mathrm{L}$ aliquot of each orange juice extract:ethanol solutions from nonprocessed, pasteurized and pressurized juice was mixed with $3 \mathrm{~mL}$ of the ABTS radical solution. Absorbance was measured at $753 \mathrm{~nm}$ after $6 \mathrm{~min}$ of reaction in a spectrophotometer (Evolution 220, Thermo Scientific, USA). Calibration curves built with Trolox ethanolic solutions $(100-1600 \mu \mathrm{mol} / \mathrm{L})$ were used. All the antioxidant activity analyses were performed in triplicate and results were expressed as $\mu \mathrm{mol}$ Trolox $/ 100 \mathrm{~mL}$ of orange juice.

Shelf life. The pressurized and pasteurized orange juices were stored under the same refrigerated conditions at zero (after juice characterization), 23, 45, 68 and 90 days, which corresponded to $0,25,50,75$ and 100 of the shelf life of NFC (ASTM, 1993). The physicochemical parameters, extraction and quantification of bioactive compounds, and antioxidant activity were evaluated during shelf life. The non-processed juice was also analyzed at zero time (juice characterization).

\section{Statistical analysis}

Results were expressed as mean \pm standard deviation of three replicate analyses and submitted to ANOVA and Tukey (zero time) or Student's $t$ test (shelf life), both at $p \leq 0.05$, using the SigmaStat 4.0 software (Systat Software Inc., San Jose, CA). Linear regression analyses and correlation were performed for shelf life results using the Origin 8 software (Origin Lab, Northampton, MA).

\section{RESULTS AND DISCUSSION PME activity}

The pressurization conditions were chosen based on its capacity to reduce PME activity below $20 \%$. The initial count for PME activity of the non-processed orange juice was considered $100 \%$ of residual activity and under these conditions HHP successfully decreased PME residual activity to $13 \%$, nearing the residual activity foreseen $(15 \%)$ in a previous optimization study (Bisconsin-Junior et al., 2014). The pasteurization was able to reduce residual PME activity to $4 \%$ (Table 1).

Figure 1 shows linear regression of each parameter for HHP and pasteurized orange juice and confidence interval, in order to illustrate trends regarding PME residual activity and color parameters during shelf life. The heat treatment was more effective at reducing PME residual activity than HHP, however both juices remained stable under $20 \%$ of residual PME activity during shelf life. The enzyme's activity is responsible for a great part in orange juice's quality loss, causing reduction in viscosity and cloud as well as separation of phases. Orange juice pressurized at $800 \mathrm{MPa}$ at $25^{\circ} \mathrm{C}$ for 60 s resulted in $4 \%$ residual PME activity, showing stability for over 90 days at $4{ }^{\circ} \mathrm{C}$ and $37^{\circ} \mathrm{C}$ storage (Nienaber and Shellhammer, 2001). Orange juice processed at $700 \mathrm{MPa}$ for $60 \mathrm{~s}$ resulted in 18\% PME residual activity, also stable for over 50 days at $4{ }^{\circ} \mathrm{C}$ (Goodner et al., 1998). 
Table 1. Residual PME activity (\%), microbiological count and color parameters of pressurized (HHP), pasteurized and non-processed orange juice at zero time of storage

\begin{tabular}{llll}
\hline Parameter & Non-processed & HHP & Pasteurized \\
\hline Residual PME activity (\%) & $100.00 \pm 6.85$ & $13.19 \pm 2.15$ & $4.24 \pm 0.29$ \\
Mesophilic aerobic (CFU/mL) & $1.03 \times 10^{2} \pm 2.1 \times 10$ & $\mathrm{ND}$ & $\mathrm{ND}$ \\
Yeast and mold (CFU/mL) & $3.6 \times 10 \pm 1.5 \times 10$ & $\mathrm{ND}$ & $\mathrm{ND}$ \\
Total coliform (CFU/mL) & $<10$ & $\mathrm{ND}$ & $\mathrm{ND}$ \\
Thermotolerant coliform (CFU/mL) & $\mathrm{ND}$ & $\mathrm{ND}$ & $\mathrm{ND}$ \\
$L^{*}$ & $41.38 \mathrm{c} \pm 0.16$ & $42.47 \mathrm{~b} \pm 0.27$ & $45.68 \mathrm{a} \pm 0.07$ \\
$a^{*}$ & $-1.78 \mathrm{a} \pm 0.03$ & $-1.32 \mathrm{~b} \pm 0.11$ & $-1.21 \mathrm{~b} \pm 0.05$ \\
$b^{*}$ & $16.13 \mathrm{c} \pm 0.24$ & $18.35 \mathrm{~b} \pm 0.42$ & $22.21 \mathrm{a} \pm 0.12$ \\
Chroma & $16.22 \mathrm{c} \pm 0.23$ & $18.40 \mathrm{~b} \pm 0.41$ & $22.24 \mathrm{a} \pm 0.12$ \\
Hue angle & $83.70 \mathrm{c} \pm 0.17$ & $85.87 \mathrm{~b} \pm 0.43$ & $86.87 \mathrm{a} \pm 0.13$ \\
Total color difference & $0.00 \mathrm{c} \pm 0.00$ & $2.52 \mathrm{~b} \pm 0.77$ & $7.52 \mathrm{a} \pm 0.13$ \\
\hline
\end{tabular}

CFU: colony formation units; ND: not detected; Chroma $=\sqrt{a^{* 2}+b^{* 2}}$; Hue angle $=$ arctangent $\left(b^{*} / a^{*}\right)$; total color difference $=\sqrt{\left(\mathrm{L}^{*^{\prime}}-\mathrm{L} * 0\right)^{2}+\left(\mathrm{a}^{*^{\prime}}-\mathrm{a} * 0\right)^{2}+\left(\mathrm{b}^{*^{\prime}}-\mathrm{b} * 0\right)^{2} \text {. }}$

Values are mean \pm standard deviation $(n=3)$. Different letter in each row indicate significant difference in Tukey test $(p \leq 0.05)$.

\section{Microbiological quality of orange juice}

Total coliform count was below detection levels for all the juices at characterization and along shelf life (AOAC, 2011). The mesophilic aerobic count in the non-processed juice was $10.2 \times 10^{2} \mathrm{CFU} / \mathrm{mL}$, and yeast and mold $3.67 \times 10^{2} \mathrm{CFU} / \mathrm{mL}$. After treatment, both pressurized and pasteurized juice effectively reduced microbiological count below detection levels.

At each period of time during shelf life the pasteurized and pressurized juice were plated and microbiological count was performed. Counts were below detection levels up to 68 days of storage for both juices. At 90 days of storage (estimated shelf life), pasteurized juice had mesophilic aerobic bacteria growth of $12.3 \times 10 \mathrm{CFU} / \mathrm{mL}$ and $2.3 \times 10 \mathrm{CFU} / \mathrm{mL}$ for yeast and mold, while pressurized juice had $30.0 \times 10 \mathrm{CFU} / \mathrm{mL}$ and $20.7 \times 10 \mathrm{CFU} / \mathrm{mL}$ of mesophilic aerobic bacteria and yeast and mold growth, respectively, but there was no visual indication of microbiological growth in the juices. At 99 days (110\% of shelf life) both HHP and pasteurized orange juices showed visible microbiological growth, indicating that they had lost their quality and that the estimated shelf life was of 90 days.

\section{Color}

Both HHP and pasteurized orange juices exhibited a slightly lower lightness $\left(L^{*}\right)$ compared to the nonprocessed juice $(p \leq 0.05)$, and values remained stable during shelf life, with only a slight reduction at 90 days for the HHP juice. The $a^{*}$ values were significantly higher for HHP and pasteurized juice compared to the non-processed juice. The same was observed for $b^{*}$ values, meaning an increase in yellow color. HHP and pasteurized juices showed a slight increase in $a^{*}$ values and a slight decrease in $b^{*}$ values during shelf life, being significantly different $(p \leq 0.05)$ over time (Table 1, Figure 1). Confidence interval could not be showed for $a^{*}$ parameter because of visual overlapping data. No changes in $L^{*}$ values for Navel oranges, pressurized at $400 \mathrm{MPa}, 40^{\circ} \mathrm{C}$ for $60 \mathrm{~s}$ were found (SánchezMoreno et al., 2005). An increase in yellow color $\left(b^{*}\right)$ after juice pasteurization of Navel oranges was observed (Cortés et al., 2008). The same trend regarding color change during shelf life (slight $L^{*}$ value decrease, $a^{*}$ value increase and $b^{*}$ value decrease) (Figure 1) was also reported by Timmermans et al. (2011) using Valencia, Pêra and Baladi oranges during 68 days of storage at $5{ }^{\circ} \mathrm{C}$. Pomegranate juice treated at $450 \mathrm{MPa}$ for $90,150 \mathrm{~s}$ and $550 \mathrm{MPa}$ showed an increase in $a^{*}$ values (Varela-Santos et al., 2012), similar to our results.

Chroma and Hue angle were higher in HHP and pasteurized juices $(p \leq 0.05)$, remaining mostly stable during shelf life, and presenting a slight decrease over time for both juices (Table 1, Figure 1). Total color difference indicates the magnitude of the non-processed juice's color difference in relation to the pressurized and pasteurized juice. Both HHP and pasteurized juices exhibited total color difference value higher than 2 , which indicates that it is possible to visually notice the color difference among the juices, as reported by Francis and Clydesdale (1975). Similar results were obtained by Cortés et al. (2008), which observed an increase in chroma after pasteurization of orange 


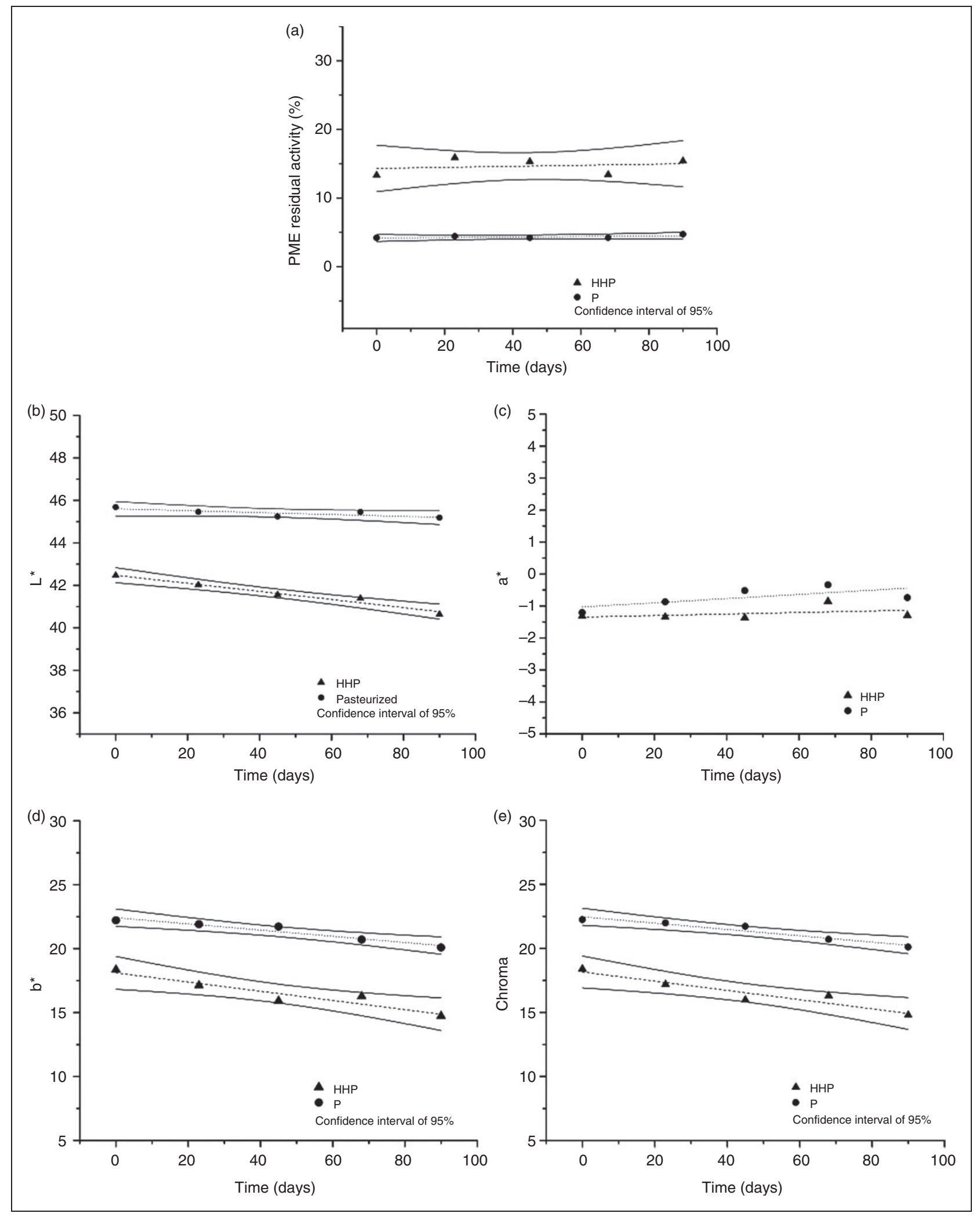

Figure 1. Residual PME activity (\%), $L^{*}, a^{*}, b^{*}$ and Chroma parameters for pressurized (HHP) and pasteurized (P) orange juice during shelf life. 
juice and high intensity pulsed electric field. An increase in Hue angle was also observed after pasteurization of orange juice (Lee and Coates, 2003). Total color difference was significantly higher in treated pomegranate juice sample at 350, 450 and $550 \mathrm{MPa}$ compared to a control untreated sample, and a decrease was observed during storage (Varela-Santos et al., 2012). Additionally, a study conducted with pumpkin puree treated with HHP found that color was better preserved (total color difference lower than 2) when using lower pressure levels (400 $\mathrm{MPa}$ rather than $600 \mathrm{MPa}$ ) and treatment time (200s rather than 600s) (GonzálezCebrino et al., 2015).

\section{Physicochemical analysis}

The physicochemical characteristics for the non-processed, pressurized and pasteurized orange juice at zero time are in Table 2. Soluble solids were similar among the non-processed, pressurized and pasteurized orange juice $(p \leq 0.05)$. The non-processed juice exhibited higher total titratable acidity $(p \leq 0.05)$ and no difference was found between the pasteurized and pressurized juices $(p>0.05)$. Both pressurized and pasteurized juices $(p>0.05)$ showed higher ratio compared to the non-processed juice $(p \leq 0.05)$. There was no significant difference in $\mathrm{pH}$ for all juices. Reducing and total sugar exhibited similar values, with significant differences for pressurized juice $(p \leq 0.05)$ (Table 2).

As reported by Bull et al. (2004) and SánchezMoreno et al. (2005), pasteurization also led to an increase in soluble solids in Navel and Valencia oranges, similar to our results. A reduction in total titratable acidity was also observed after pasteurization using Navel oranges (Sánchez-Moreno et al., 2005).

Figure 2 shows the shelf life results for both pasteurized and pressurized orange juice which exhibited stability in all parameters, as well as no significant differences between the juices $(p>0.05)$, indicating that both HHP and pasteurization did not impact the juice shelf life. Orange juice submitted to HHP and thermal treatment from Valencia and Navel oranges, stored at 4 and $10{ }^{\circ} \mathrm{C}$, showed no significant difference in physicochemical parameters between both juices and untreated juice, as well as no changes during storage $(p>0.05)$ (Bull et al., 2004). Similarly, orange juice pasteurized at $92{ }^{\circ} \mathrm{C}$ for $30 \mathrm{~s}$ showed no significant changes during 32 weeks of storage for $\mathrm{pH}$ and total titratable acidity (Wibowo et al., 2015).

\section{Bioactive compounds and antioxidant activity}

Ascorbic acid. The non-processed orange juice showed higher AA levels $(p \leq 0.05)$ compared to the pressurized and pasteurized juice, as expected (Table 2). The pasteurized juice presented higher AA than the pressurized juice $(p \leq 0.05)$. Plaza et al. (2006) reported that HHP reduced AA levels of Valencia oranges in 5\% and Sánchez-Moreno et al. (2005) reported AA reduction of $8 \%$ in Navel oranges submitted to $400 \mathrm{MPa}$, at $40{ }^{\circ} \mathrm{C}$ for $60 \mathrm{~s}$. The higher temperature and time conditions applied in this work (520 $\left.\mathrm{MPa}, 60^{\circ} \mathrm{C}, 360 \mathrm{~s}\right)$ resulted in a higher reduction of AA levels $(16 \%)$. Similarly, pasteurization reduced AA levels in $13 \%$, lower than a $17 \%$ decrease as reported by Elez-Martínez et al. (2006), and higher than the reduction of $8 \%$ reported by SánchezMoreno et al. (2005) after pasteurizing orange juice at $90^{\circ} \mathrm{C}$ for $60 \mathrm{~s}$.

It should be noticed that our results for AA levels for non-processed, pressurized and pasteurized orange juice were in the same range of Brazilian (Stella et al., 2011) and Spanish (Meléndez-Martínez et al., 2007) orange juice.

Table 2. Physicochemical characteristics, total phenolic content and antioxidant activity of pressurized (HHP), pasteurized and non-processed orange juice at zero time of storage

\begin{tabular}{lccc}
\hline Parameter & Non-processed & HHP & Pasteurized \\
\hline Soluble solids ( ${ }^{\circ}$ Brix) & $9.5 \mathrm{~b} \pm 0.1$ & $9.5 \mathrm{~b} \pm 0.0$ & $9.7 \mathrm{a} \pm 0.1$ \\
Total titratable acidity (g citric acid/100 mL) & $0.9 \mathrm{a} \pm 0.0$ & $0.6 \mathrm{~b} \pm 0.0$ & $0.6 \mathrm{~b} \pm 0.0$ \\
Ratio & $10.9 \mathrm{~b} \pm 0.1$ & $16.0 \mathrm{a} \pm 0.1$ & $16.0 \mathrm{a} \pm 0.1$ \\
$\mathrm{pH}$ & $4.06 \mathrm{a} \pm 0.01$ & $4.07 \mathrm{a} \pm 0.04$ & $4.05 \mathrm{a} \pm 0.04$ \\
Reducing sugar $(\mathrm{g}$ glucose $/ 100 \mathrm{~mL})$ & $3.7 \mathrm{a} \pm 0.0$ & $3.5 \mathrm{~b} \pm 0.0$ & $3.7 \mathrm{a} \pm 0.0$ \\
Total sugar $(\mathrm{g}$ glucose $/ 100 \mathrm{~mL})$ & $7.1 \mathrm{a} \pm 0.0$ & $6.6 \mathrm{~b} \pm 0.0$ & $7.1 \mathrm{a} \pm 0.1$ \\
Ascorbic acid $(\mathrm{mg} / 100 \mathrm{~mL})$ & $38.3 \mathrm{a} \pm 0.3$ & $32.2 \mathrm{c} \pm 0.2$ & $33.3 \mathrm{~b} \pm 0.3$ \\
Total phenolic compounds & $52.85 \mathrm{a} \pm 2.8$ & $52.76 \mathrm{a} \pm 3.9$ & $52.62 \mathrm{a} \pm 2.2$ \\
$\quad(\mathrm{mg}$ gallic acid equivalent/100 $\mathrm{mL})$ & & & \\
ABTS $(\mu \mathrm{mol}$ Trolox/100 $\mathrm{mL})$ & $302.3 \mathrm{a} \pm 2.0$ & $299.1 \mathrm{a} \pm 2.4$ & $294.7 \mathrm{a} \pm 8.3$ \\
\hline
\end{tabular}

Values are mean \pm standard deviation $(n=3)$ and same letter in each row did not indicate significant difference in Tukey test $(p \leq 0.05)$. 

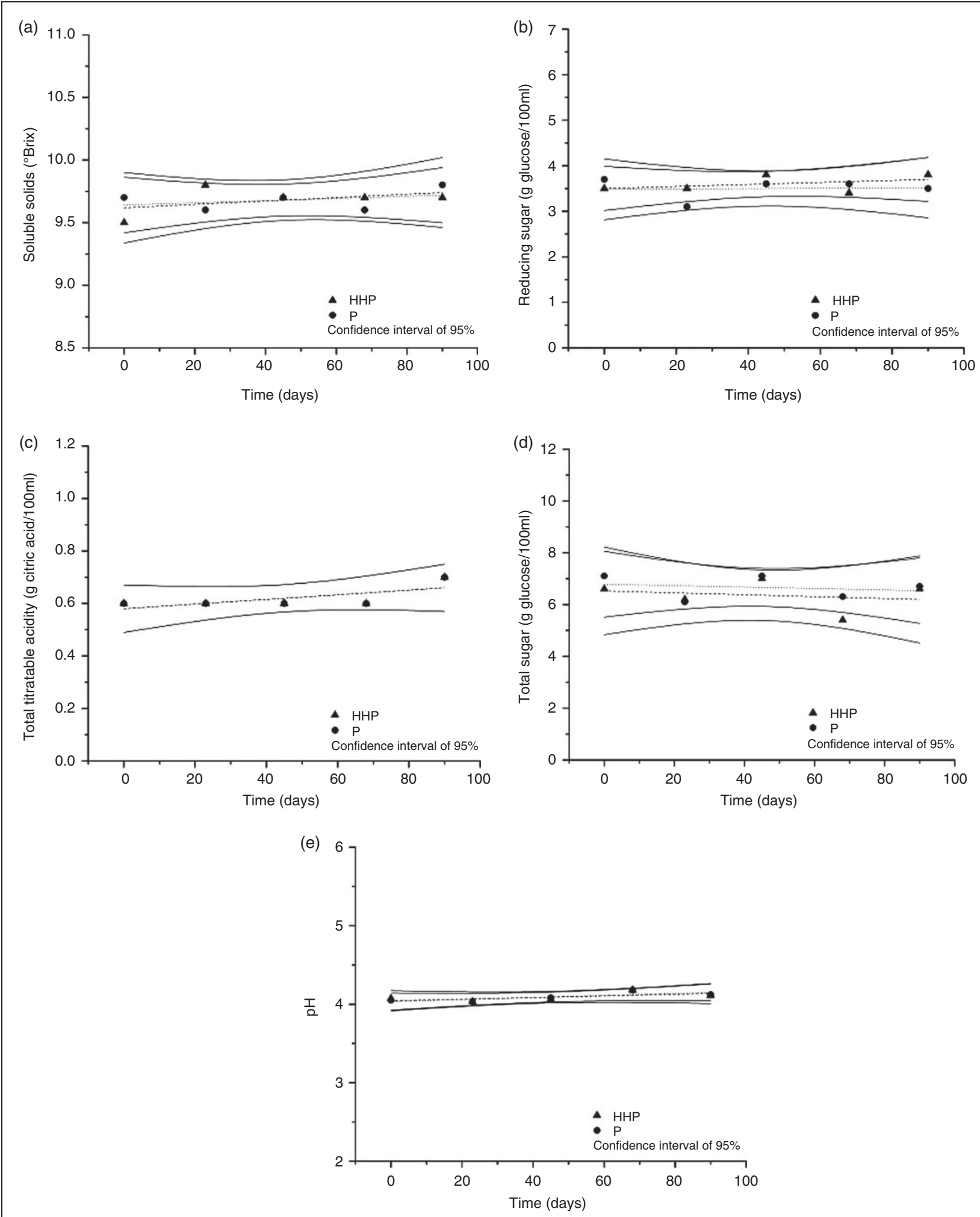

Figure 2. Physicochemical characteristics for pressurized (HHP) and pasteurized (P) orange juice during shelf life. 
Figure 3 shows AA levels during storage. Both pressurized and pasteurized juice exhibit the same strong reduction over time $(p \leq 0.05)$, reducing around $70-80 \%$ of AA levels in 90 days. Ascorbic acid degradation is due to many factors, including type of processing, storage conditions, packaging, oxygen, and light (Shaw and Moshonas, 1991; Teixeira and Monteiro, 2006). The results obtained in our study indicate that a very strong decrease in AA levels occurred during shelf life. Similar results were obtained using Valencia and Navel oranges, which presented a reduction in AA during a three-month storage at $4{ }^{\circ} \mathrm{C}$ (Bull et al., 2004). Nienaber and Shellhammer (2001) attributed AA level reduction to its oxidation over time.

Total phenolic compounds. The results for TPC are in Table 2. Non-processed, pasteurized and pressurized orange juice showed no significant difference at zero time, indicating that TPC is resistant to both HHP and thermal treatment. Some studies suggest that TPC may even increase with processing, when antioxidants can be more extracted (Chen et al., 2015; VarelaSantos et al, 2012).

Both pressurized and pasteurized orange juice exhibited the same behavior during shelf life regarding TPC, with a slight decrease over time, and no significant difference between them $(p>0.05)$. Comparative literature on the effects of HHP on TPC for orange juice is scarce; however, a few studies have showed this influence on different fruit juices. A study using papaya beverage treated with HHP and pasteurization, stored at $4{ }^{\circ} \mathrm{C}$ showed similar results, with comparable small decrease rate over time, although HHP retained TPC better than pasteurization (Chen et al., 2015). Similarly, a study with mulberry juice, compared thermal treatment $\left(85^{\circ} \mathrm{C}, 15 \mathrm{~min}\right)$ with $\mathrm{HHP}(500 \mathrm{MPa}, 10 \mathrm{~min})$, and found that HHP was able to retain more TPC (Wang et al., 2016). Varela-Santos et al. (2012) found that pomegranate juice processed with HHP showed slight decrease during storage of 35 days at $4{ }^{\circ} \mathrm{C}$.

Antioxidant activity. Results of antioxidant activity are given in Table 2. Antioxidant activity of pressurized, non-processed and pasteurized orange juice using ABTS radical assay ranged from 294.7 to $302.3 \mu \mathrm{mol}$ Trolox $/ 100 \mathrm{~mL}$, with no significant difference between pressurized and pasteurized orange juice $(p>0.05)$. The antioxidant activity levels obtained with ABTS were in the range of those reported by Stella et al. (2011) for Brazilian orange juice. Other studies showed that antioxidant activity was not significantly affected after HHP at $440 \mathrm{MPa}, 40^{\circ} \mathrm{C}$ for $60 \mathrm{~s}$ and pasteurization (Gil-Izquierdo et al., 2002; Sánchez-Moreno et al., 2005). Gonzáles-Cebrino et al. (2015) were able to show that HHP, while using different pressures and holding times, was effective in maintaining total antioxidant activity levels in pumpkin puree.

ABTS shows a slight increase during shelf life and overall antioxidant activity for both juices maintained high values along shelf life (Figure 3). It has been reported that HHP can either increase or maintain
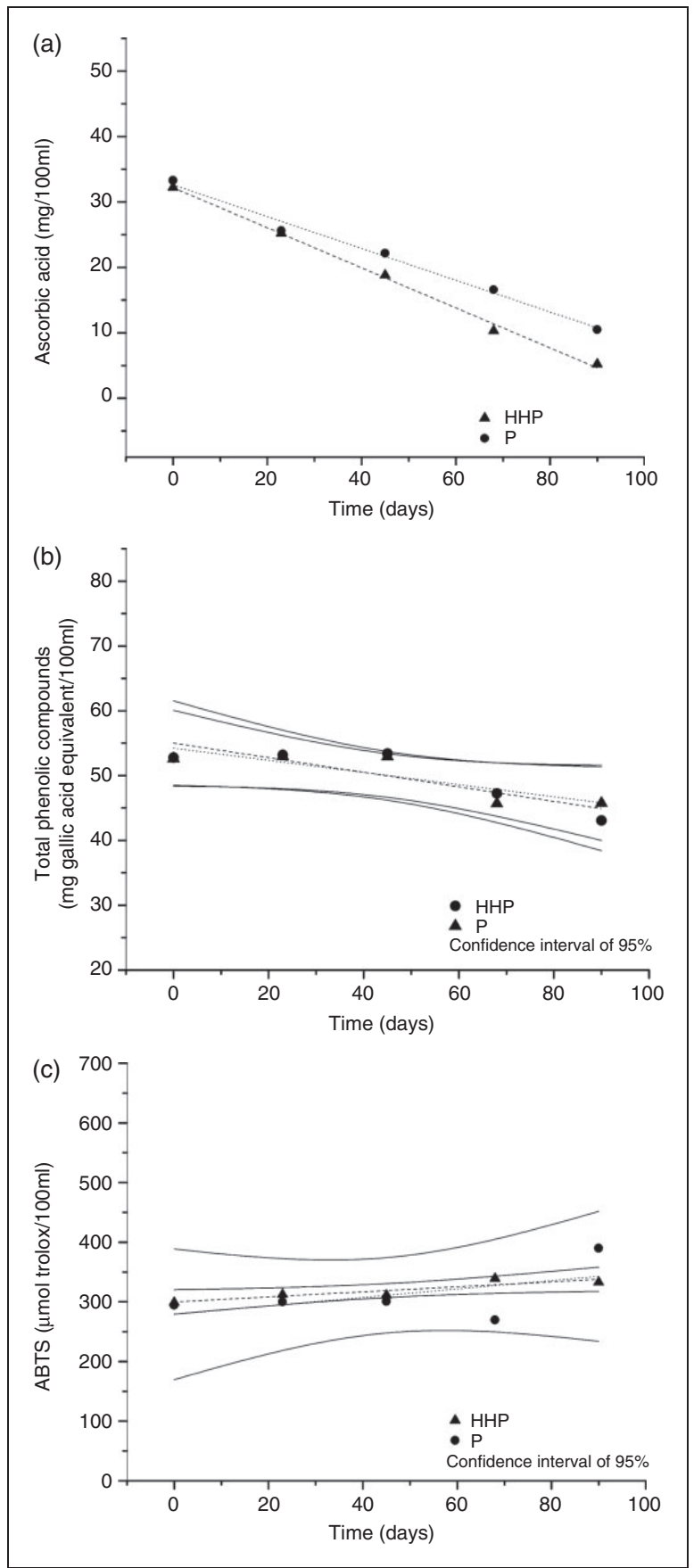

Figure 3. Ascorbic acid (mg/100 mL), total phenolic compounds (mg gallic acid equivalent $/ 100 \mathrm{~mL}$ ), and antioxidant activity ( $\mu \mathrm{mol}$ Trolox/100 mL) in pressurized (HHP) and pasteurized $(P)$ orange juice during shelf life. 
antioxidant levels, depending of pressure and time conditions (Casquete et al., 2015).

Antioxidant activity, TPC, and AA correlation. Correlation among antioxidant activity, TPC, and AA was determined for HHP and pasteurized orange juice during shelf life. The correlation coefficient between TPC and AA was positive and strong for both juices $(r=0.8693$ and $r=0.8324$, respectively for HHP and pasteurized). A positive and strong correlation was obtained between TPC and ABTS for HHP juice $(r=0.8322)$, and a positive weak $(r=0.3651)$ for pasteurized juice. ABTS and AA presented a very strong and positive correlation for HHP juice $(r=0.9249)$ and moderate and positive correlation for pasteurized juice $(r=0.5716)$.

In a general way, the results indicate that HHP preserved the characteristics of Pêra-Rio orange juice during shelf life, as well as pasteurization, as it did not affect greatly the juice's overall quality and microbiological and enzymatic stability. However, further research is still required. The research group's next step will be an olfatometric and sensorial analysis, in order to explore consumer acceptance of HHP on the juice's aroma.

\section{CONCLUSION}

Pressurization did not cause expressive change in physicochemical characteristics of Pêra-Rio orange juice during a refrigerated 90-day shelf life period, but did significantly reduce PME activity and microbiological count, capable of ensuring the juice's stability along shelf life. The orange juice color was slightly affected by HHP over time. Ascorbic acid strongly decreased during shelf life. Antioxidant activity remained mostly stable after processing and during storage. HHP of Pêra-Rio orange juice, maintained the juice's overall quality and ensured microbiological safety and enzymatic stability, rendering it a promising technology for the citrus industry.

\section{ACKNOWLEDGEMENT}

The authors would like to thank JBT FoodTech, Araraquara, SP, Brazil for supplying the orange juice.

\section{DECLARATION OF CONFLICTING INTERESTS}

The author(s) declared no potential conflicts of interest with respect to the research, authorship, and/or publication of this article.

\section{FUNDING}

The author(s) disclosed receipt of the following financial support for the research, authorship, and/or publication of this article: FAPESP (São Paulo Research Foundation) for financial support (no. 2013/00424-5 and 2011/11574-2).

\section{ORCID iDs}

Antonio Bisconsin-Junior (D) http://orcid.org/0000-00019474-1691

Magali Monteiro (D) http://orcid.org/0000-0002-5436-2598

\section{REFERENCES}

Asami DK, Hong YJ, Barrett DM and Mitchell AE. (2003). Comparison of the total phenolic compounds and ascorbic acid content of freeze-dried and air-dried marionberry, strawberry, and corn grown using conventional, organic, and sustainable agricultural practices. Journal of Agricultural and Food Chemistry 51(5): 1237-1241.

Association of Official Analytical Chemists (AOAC). (2011). Official Methods of Analysis. Gaithersburg: Association of Official Analytical Chemists.

ASTM. (1993). Standard guide for the shelf life determination of consumer products by sensory evaluation. Philadelphia, 10 p (ASTM 18.06.07).

Baxter IA, Easton K, Schneebeli K and Whitfield FB. (2005). High pressure processing of Australian navel orange juices: sensory analysis and volatile flavor profiling. Innovative Food Science and Emerging Technologies 6(4): 372-387.

Bisconsin-Junior A, Alvarenga JFR, Rosenthal A and Monteiro M. (2015). Effect of high hydrostatic pressure on ascorbic acid, phenolic compounds and antioxidant activity of Pera Rio orange juice. Journal of Food Processing \& Technology 6(2): 416.

Bisconsin-Junior A, Rosenthal A and Monteiro M. (2014). Optimisation of high hydrostatic pressure processing of Pêra Rio orange juice. Food and Bioprocess Technology 7(6): 1670-1677.

Braddock RJ. (1999). Single strength orange juices and concentrate. Handbook of Citrus By-products and Processing Technology. New York, NY: John Wiley \& Sons, pp. 53-83.

Bull MK, Zerdin K, Howe E, Goicoechea D, Paramanandhan P, Stockman R, et al. (2004). The effect of high pressure processing on the microbial, physical and chemical properties of Valencia and Navel orange juice. Innovative Food Science and Emerging Technologies 5: 135-149.

Casquete R, Castro SM, Martin A, Ruiz-Moyano S, Saraiva JA, Córdoba MG, et al. (2015). Evaluation of the effect of high pressure on total phenolic content, antioxidant and antimicrobial activity of citrus peels. Innovative Food Science \& Emerging Technologies 31: 37-44.

Chen D, Pang X, Zhao J, Gao L, Liao X, Wu J, et al. (2015). Comparing the effects of high hydrostatic pressure and high temperature short time on papaya beverage. Innovative Food Science and Emerging Technologies 32: $16-28$.

CITRUSBR. (2017). Associação Nacional dos Exportadores de Sucos de Cítricos. Estimativas de Safras. Available at: http://www.citrusbr.com.br/safras/ (accessed 1 April 2017).

Cortés C, Esteve MJ and Frígola A. (2008). Color of orange juice treated by high intensity pulsed electric fields during 
refrigerated storage and comparison with pasteurized juice. Food Control 19(2): 151-158.

Deliza R, Rosenthal A, Abadio FBD, Silva CHO and Castillo C. (2005). Application of high pressure technology in the fruit juice processing: Benefits perceived by consumers. Journal of Food Engineering 67: 241-246.

Elez-Martínez P, Soliva-Fortuny RC and Martín-Bellos O. (2006). Comparative study on shelf life of orange juice processed by high intensity pulsed electric fields or heat treatment. European Food Research and Technology 222(3-4): 321-329.

Francis FJ and Clydesdale FM. (1975). Food Colorimetry: Theory and Applications. Westport, Connecticut, USA: The AVI Publishing Company, Inc., p. 477.

Gil-Izquierdo A, Gil MI and Ferreres F. (2002). Effect of processing techniques at industrial scale on orange juice antioxidant and beneficial health compounds. Journal of Agricultural and Food Chemistry 50(18): 5107-5114.

González-Cebrino F, Durán R, Delgado-Adámez J, Contador R and Bernabé RR. (2015). Impact of high pressure processing on color, bioactive compounds, polyphenol oxidase activity, and microbiological attributes of pumpkin pureé. Food Science and Technology International 22(3): 235-245.

Goodner JK, Braddock RJ and Parish ME. (1998). Inactivation of pectinesterase in orange and grapefruit juices by high pressure. Journal of Agricultural and Food Chemistry 46(5): 1997-2000.

Hagerman AE and Austin PJ. (1986). Continuous spectrophotometric assay for plant pectin methyl esterase. Journal of Agricultural and Food Chemistry 34(3): 440-444.

Instituto de Economia Agrícola (IEA). (2017). Instituto de Economia Agrícola. Available at: http://www.iea.sp.gov. br/ (accessed in 22 March 2017).

Janzantti NS, Machado TV and Monteiro M. (2011). Sensory acceptance of juice from FCOJ processing steps. Journal of Sensory Studies 26: 322-330.

Lee HS and Coates GA. (2003). Effect of thermal pasteurization on Valencia orange juice color and pigments. Food Science and Technology 36(1): 153-156.

Meléndez-Martínez AJ, Vicario IM and Heredia FJ. (2005). Instrumental measurement of orange juice colour: A review. Journal of the Science of Food and Agriculture 85(6): 894-901.

Meléndez-Martínez AJ, Vicario IM and Heredia FJ. (2007). Provitamin A carotenoids and ascorbic acid contents of the different types of orange juices marketed in Spain. Food Chemistry 101(1): 177-184.

Nienaber U and Shellhammer TH. (2001). High-pressure processing of orange juice: Combination treatments and a shelf life study. Journal of Food Science 66(2): 332-336.

Plaza L, Sánchez-Moreno C, Elez-Martinéz P, De Ancos B, Martín-Belloso O and Pilar Cano M. (2006). Effect of refrigerated storage on vitamin $\mathrm{C}$ and antioxidant activity of orange juice processed by high-pressure or pulsed electric fields with regard to low pasteurization. European Food Research and Technology 223(4): 487-493.

Rodrigues MI and Iemma AF. (2009). Planejamento de Experimentos e Otimização de Processos. 238 p. Ed Cárita, Campinas, Brazil.
Rufino MSM, Alves RE, Brito ES, Perez-Jimenez J, SauraCalixto F and Mancini-Filho J. (2010). Bioactive compounds and antioxidant capacities of 18 non-traditional tropical fruits from Brazil. Food Chemistry 121(4): 996-1002.

Sánchez-Moreno C, Plaza L, Elez-Martinéz P, de Ancos B, Martín-Belloso O and Cano MP. (2005). Impact of high pressure and pulsed electric fields on bioactive compounds and antioxidant activity of orange juice in comparison with traditional thermal processing. Journal of Agricultural and Food Chemistry 53(11): 4403-4409.

Secretaria de Comércio Exterior (SECEX). (2017). Secretaria de Comércio Exterior. Available at: http://www.desenvolvimento.gov.br/sitio/interna/index.php?area $=5$ (accessed 23 March 2017).

Shaw PE and Moshonas MG. (1991). Ascorbic acid retention in orange juice stored under simulated consumer home conditions. Journal of Food Science 56: 867-868.

Singleton VL, Orthofer R and Lamuela-Raventós RM. (1999). Analysis of total phenols and other oxidation substrates and antioxidants by means of folin-ciocalteu reagent. Methods in Enzymology 299: 152-178.

Stella SP, Ferrarezi AC, Santos KO and Monteiro M. (2011). Antioxidant activity of commercial ready-to-drink orange juice and nectar. Journal Food Science 76(3): 392-397.

Teixeira M and Monteiro M. (2006). Degradação da vitamina C em suco de fruta. Alimentos e Nutrição 17(2): 219-227.

Timmermans RAH, Mastwijk HC, Knol JJ, Quataert MCJ, Vervoort L, Van der Plancken I, et al. (2011). Comparing equivalent thermal, high pressure and pulsed electric field processes for mild pasteurization of orange juice. Part I: Impact on overall quality attributes. Innovative Food Science and Emerging Technologies 12(3): 235-243.

Torres EF, González MG, Klotz B and Rodrigo D. (2015). Effects of high hydrostatic pressure and temperature increase on Escherichia coli spp. and pectin methyl esterase inactivation in orange juice. Food Science and Technology International 22(02): 173-180.

United States Department of Agriculture (USDA). (2017). Disponível em. Available at: http://www.usda.gov/wps/ portal/usda/usdahome (accessed 22 March 2017).

Varela-Santos E, Ochoa-Martinez A, Tabilo-Munizaga G, Reyes JE, Pérez-Won M, Briones-Labarca V, et al. (2012). Effect of high hydrostatic pressure (HHP) processing on physicochemical properties, bioactive compounds and shelf-life of pomegranate juice. Innovative Food Science and Emerging Technologies 13: 13-22.

Versteeg C, Rombouts FM, Spaansen CH and Pilnik W. (1980). Thermostability and orange juice cloud destabilizing properties of multiple pectinesterases from orange. Journal of Food Science 45(4): 969-971.

Vervoort L, Van Der Plancken I, Grauwet T, Timmermans RH, Mastwijk HC, Matser AM, et al. (2011). Comparing equivalent thermal, high pressure and pulsed electric field processes for mild pasteurization of orange juice. Part II: Impact on specific chemical and biochemical quality parameters. Innovative Food Science and Emerging Technologies 12(4): 466-477. 
Wang F, Du B, Cui Z, Xu LP and Li CY. (2016). Effects of high hydrostatic pressure and thermal processing on bioactive compounds, antioxidant activity, and volatile profile of mulberry juice. Food Science and Technology International 23(2): 119-127.
Wibowo S, Grauwet T, Santiago J, Tomic J, Vervoort L, Hendrickx M, et al. (2015). Quality changes of pasteurised orange juice during storage: A kinetic study of specific parameters and their relation to colour instability. Food Chemistry 187: 140-151. 